\title{
Unscheduled bleeding and contraceptive choice: increasing satisfaction and continuation rates
}

\author{
This article was published in the following Dove Press journal: \\ Open Access Journal of Contraception \\ 31 March 2016 \\ Number of times this article has been viewed
}

\section{Jennifer Villavicencio Rebecca H Allen}

The Department of Obstetrics and Gynecology, Women and Infants Hospital of Rhode Island, Warren Alpert Medical School of Brown University, Providence, RI, USA
Correspondence: Rebecca H Allen

The Department of Obstetrics and Gynecology, Warren Alpert Medical School of Brown University, I0I Dudley Street, Providence, RI, 02905, USA

Email rhallen@wihri.org

\begin{abstract}
Approximately half (51\%) of the 6.6 million pregnancies in the US each year are unintended and half of those pregnancies (54\%) occur among women not using contraception. Many women discontinue their contraceptives due to method dissatisfaction. Bothersome unscheduled bleeding is one of the main reasons cited by women for stopping a birth control method. Improving counseling and management of these side effects will aide in increasing satisfaction with contraceptive methods. The following review will discuss the bleeding profiles associated with the contraceptive options available in the US. A valuable resource from the Centers for Disease Control and Prevention, the US Selected Practice Recommendations for Contraceptive Use, will be introduced. Definitions of the types of unscheduled bleeding are included, as well as strategies for treatment for each contraceptive method. The evidence whether or not anticipatory counseling increases continuation rates will also be reviewed.
\end{abstract}

Keywords: unscheduled uterine bleeding, contraception, drug treatment, patient satisfaction

\section{Introduction}

The unintended pregnancy rate in the US remains at nearly $50 \%$ and half of those pregnancies occur among women not using contraception. ${ }^{1}$ It is important to address issues that women face in accessing contraception, using it correctly, and continuing to use it consistently. Many components of contraceptive use must be considered when choosing a contraceptive method including effectiveness, safety, access, and acceptability. Discontinuation rates are an important aspect to consider when counseling patients regarding the optimal contraceptive for their lifestyle. Reasons for discontinuing contraceptives are not well captured in many studies. ${ }^{2}$ Women may discontinue contraceptives for reasons other than side effects, such as logistical issues in filling prescriptions or returning to the site of care or their inability to adhere to the method. ${ }^{3}$ Women may also start and stop contraceptives on their own. Nevertheless, among the $46 \%$ of women who discontinue their birth control due to dissatisfaction, one of the more common reasons is unfavorable bleeding profile. ${ }^{4,5}$ The bleeding profile of a contraceptive is defined by its effects on uterine bleeding which can include regular withdrawal bleeding, amenorrhea, irregular spotting/bleeding, or heavy, prolonged bleeding. Counseling women regarding anticipated bleeding side effects with their chosen contraceptive method is important. In addition, the ability to offer treatments for bothersome bleeding is critical to improving contraceptive satisfaction and continuation rates. 


\section{General guidelines}

The definitions of unscheduled bleeding associated with contraceptive use are listed in Table $1 .{ }^{6}$ These definitions are typically used for research studies evaluating contraceptives. ${ }^{6}$ Nevertheless, they are useful for data comparisons across trials. While unscheduled bleeding can be a side effect of the contraceptive method, it is important to remember that other causes of bleeding may need to be investigated depending on the clinical situation. For example, pregnancy, cervicitis or cervical dysplasia, sexually transmitted infections, and uterine conditions such as fibroid, polyp, endometrial hyperplasia or cancer are all possible causes of bleeding. ${ }^{1}$ In the case of intrauterine devices (IUDs), displacement or expulsion should be ruled out. Amenorrhea while using hormonal contraceptives, in the absence of pregnancy, is not a concerning symptom and does not require treatment.

One of the most important aspects of contraceptive prescription is anticipatory counseling. Side effect profiles can be a predominating factor in women's decision making regarding which contraception to use and whether or not to continue the method. ${ }^{1,7}$ A Cochrane review investigating strategies to improve adherence to hormonal contraceptive methods looked specifically at anticipatory guidance and the role it played in women's use of contraceptives. The conclusion of the review indicated that a structured discussion regarding side effects of contraception and multiple, ongoing discussions regarding these (eg, phone calls) had the potential to improve use of oral contraceptives (OCs) and injectable hormonal contraceptives. ${ }^{7}$ A more recent randomized trial by Modesto et al from Brazil investigated whether intensive counseling was superior to routine counseling in improving discontinuation rates due to unscheduled bleeding among 300 women using IUDs (copper $[\mathrm{Cu}]$ and levonorgestrel

Table I Definitions of unscheduled bleeding patterns

\begin{tabular}{ll}
\hline Bleeding & $\begin{array}{l}\text { Evidence of blood loss that requires the use } \\
\text { of sanitary protection with a tampon, pad or } \\
\text { pantyliners } \\
\text { Evidence of minimal blood loss that does } \\
\text { not require use of any type of sanitary } \\
\text { protection, including pantyliners }\end{array}$ \\
& $\begin{array}{l}\text { Bleeding/spotting days bounded on either } \\
\text { end by } 2 \text { days of no bleeding or spotting } \\
\text { Episode of bleeding/ }\end{array}$ \\
spotting & $\begin{array}{l}\text { Less than three bleeding and/or spotting } \\
\text { Infrequent bleeding }\end{array}$ \\
Prolonged bleeding & $\begin{array}{l}\text { more than } 14 \text { days in } 90 \text { days } \\
\text { more than five bleeding and/or spotting }\end{array}$ \\
Frequent bleeding & $\begin{array}{l}\text { More thas } \\
\text { episodes in } 90 \text { days } \\
\text { No bleeding and/or spotting in } 90 \text { days }\end{array}$ \\
\hline
\end{tabular}

[LNG]) and the etonogestrel implant. ${ }^{8}$ The routine counseling group received 15 minutes of counseling from nurses who discussed anatomy for IUDs, effectiveness, non-contraceptive benefits, side effects, what to expect in terms of unpredictable bleeding, return to fertility, and mechanism of action. The intensive counseling group received additional information including reviewing a pamphlet that explained in depth the changes in bleeding patterns that might occur due to the method chosen, the reason the bleeding abnormalities might occur, and possible treatment options for 15 more minutes. The intensive counseling group received their counseling from three experienced family planning physicians. The study found no significant difference between the two groups in discontinuation rates due to menstrual bleeding irregularities at 12 months (2.1\% implant, 2.7\% LNG-IUD, 4.0\% $\mathrm{Cu}-\mathrm{IUD}, P=0.85)$. Nevertheless, the 15 minutes spent in the routine counseling group is longer than typically allotted in US-based practices, given time constraints. Therefore, the Modesto study included more counseling in both groups than would be offered routinely in the US. However, if both the Cochrane review and the Modesto study are taken in conjunction, it can be inferred that any measure of anticipatory counseling regarding side effects and bleeding profile can be helpful in improving acceptability and continuation rates, and should be routinely offered upon initiation of a contraceptive method.

\section{Intrauterine contraception}

There are currently four IUDs available in the US: the $\mathrm{Cu}$-IUD and three LNG-IUDs (one $13.5 \mathrm{mg}$ and two $52 \mathrm{mg}$ LNG). As a form of long-acting reversible contraception (LARC), the IUD is highly effective with 1-year failure rates of $0.6 \%$ to $0.8 \%$ for the $\mathrm{Cu}-\mathrm{IUD}$ and $0.2 \%$ for the LNG-IUD. Additionally, the discontinuation rates are some of the lowest among contraceptives, with approximately $80 \%$ of women continuing use at 1 year. ${ }^{9}$ Placement of either the $\mathrm{Cu}$-IUD or LNG-IUDs can be performed at any time if it is reasonably certain the patient is not pregnant and there is no active infection of the cervix or uterus. ${ }^{1}$ The $\mathrm{Cu}$-IUD can be used as emergency contraception up to 5 days after unprotected intercourse.

\section{Copper-intrauterine device Expected bleeding irregularities and counseling}

Unscheduled bleeding including spotting or light bleeding as well as heavier, prolonged menses can be expected in approximately $70 \%$ of new users within the first 3 to 6 months 
of use. ${ }^{1,10}$ In one study of 1,947 first-time Cu-IUD users, $38 \%$ rated menstrual pain and $68 \%$ rated menstrual bleeding as "more than before using the IUD" in the first 9 weeks of use. This decreased to $33 \%$ reporting more menstrual pain and $49 \%$ reporting more menstrual bleeding at 40 weeks of use. ${ }^{11}$ The $\mathrm{Cu}$-IUD has been shown to objectively increase menstrual blood loss by 50\%. ${ }^{12}$ Women who use the Cu-IUD may have decreased hemoglobin concentrations when compared to OC users or contraceptive non-users, however it is usually not a clinically significant decrease. ${ }^{13,14}$ Anticipatory counseling is critical and patients should be counselled to expect heavier and possibly more painful menses, although for some women these symptoms may improve with time. ${ }^{11}$ Continuation rates for the $\mathrm{Cu}-\mathrm{IUD}$ in one large prospective study were $84 \%$ at 1 year, $76 \%$ at 2 years, and $70 \%$ at 3 years. ${ }^{15}$ The most common reason for discontinuation is bleeding and pain.

\section{Treatment options}

In the first 6 months, patients with bleeding irregularities should be offered reassurance and counseling. However, if a patient continues to experience bleeding irregularities that are unacceptable, there are several treatment options available. Non-steroidal anti-inflammatory drugs (NSAIDs) have been shown to diminish volume of bleeding as well as dysmenorrhea in women using the $\mathrm{Cu}$-IUD. A Cochrane review concluded that naproxen, ibuprofen, or mefenamic acid use for a short course (5 to 7 days) during the days of bleeding was effective. ${ }^{1,16}$ Despite the clinically significant effect NSAID use has on bleeding irregularities in $\mathrm{Cu}$-IUD users, several studies suggest prophylactic use does not decrease the discontinuation rate. ${ }^{16,17}$ Data regarding the overall safety of tranexamic acid are limited; however one small study among $19 \mathrm{Cu}-I U D$ users with heavy bleeding suggested significantly decreased mean blood loss during treatment in comparison with placebo. ${ }^{18}$ Aspirin has not been shown to be effective in decreasing menstrual blood loss in Cu-IUD users. ${ }^{1,19}$ Limited evidence exists regarding use of intranasal desmopressin to decrease mean blood loss. ${ }^{1,20}$

\section{Levonorgestrel-intrauterine device Expected bleeding irregularities and counseling}

The main difference between the $\mathrm{Cu}-\mathrm{IUD}$ and the LNGIUDs is that while the $\mathrm{Cu}$-IUD may increase the volume of bleeding, the LNG-IUD is associated with lighter menses and possible amenorrhea. ${ }^{1}$ Because endometrial suppression is not immediate and may take 3 to 6 months, women should be counselled that irregular bleeding as well as cramping is normal in the first 3 to 6 months after LNG-IUD insertion. This decreases over time and in many women progresses to oligomenorrhea or amenorrhea ${ }^{1}$; often this is a desired side effect of the LNG-IUD. The LNG-IUD reduces menstrual blood loss by $90 \%$ and is approved for the treatment of heavy menstrual bleeding in several countries including the US. ${ }^{21}$ Amenorrhea in the setting of LNG-IUD is caused by endometrial atrophy and does not require treatment. However, the progression to amenorrhea is usually gradual, over the course of months. If a woman experiences abrupt amenorrhea or pregnancy symptoms, pregnancy should be ruled out. Some women may find the amenorrhea to be unacceptable or unsettling; if this is the case, counseling on alternative forms of contraception is appropriate. While the above bleeding changes are common to all three of the LNGIUDs, the nuances of each are discussed below.

- LNG-IUD $52 \mathrm{mg}$ approved for 5 years (abbreviated LNG 52/5, commercial name Mirena): this IUD is most associated with oligomenorrhea/amenorrhea. In the first year of use, $20 \%$ of women using the LNG 52/5 will experience amenorrhea. ${ }^{22}$ Within the first 2 years of use, upwards of $50 \%$ of women using the LNG 52/5 may experience amenorrhea or oligomenorrhea. ${ }^{23}$ As above, if reassurance does not assuage the discomfort a patient has with the amenorrhea, alternative contraception should be discussed. Three-year continuation rates for this LNGIUD were $87 \%$ at 1 year, $77 \%$ at 2 years, and $70 \%$ at 3 years in one large prospective study. ${ }^{15}$

- LNG-IUD $52 \mathrm{mg}$ approved for 3 years (abbreviated LNG $52 / 3$, commercial name Liletta): ${ }^{24,25}$ this is the newest device and data regarding long-term bleeding profiles are currently being collected. Current data suggest the bleeding profile is very similar to that of the LNG 52/5, with $19 \%$ of women having amenorrhea at 12 months, $26 \%$ at 24 months, and $38 \%$ by 36 months. ${ }^{25}$

- LNG-IUD $13.5 \mathrm{mg}$ approved for 3 years (abbreviated LNG 13.5/3, commercial name Skyla): ${ }^{26,27}$ the 1 -year amenorrhea rate for the LNG $13.5 / 3$ is significantly lower than that of the LNG $52 / 5$ or $52 / 3$ at $6 \%$. At 3 years, the amenorrhea rate for LNG $13.5 / 3$ is $12 \% .{ }^{26}$ Women using the $13.5 / 3$ are more likely to experience monthly menstruation.

Given the differences in bleeding irregularities between the two LNG 52 IUDs and the LNG 13.5 IUD, women should be counselled according to the device they are using. Specifically, discussion with a patient regarding her preference for monthly menses, comfort with possible amenorrhea, and tolerance of intermenstrual spotting should be carried 
out. In women preferring the reassurance of a lighter monthly menses, recommendation of the LNG $13.5 \mathrm{mg}$ can be made. In women in whom the idea of oligomenorrhea or amenorrhea is appealing, the LNG $52 \mathrm{mg}$ may be the best choice.

\section{Treatment options}

As previously mentioned, amenorrhea in the setting of LNG-IUD use does not require treatment and can be managed with reassurance. After the initial 3 to 6 months of use, bleeding patterns should stabilize. If patients continue to find their symptoms unacceptable, consideration of an alternative form of contraception is appropriate. There are no trials evaluating treatments for bleeding irregularities with LNG-IUD use. ${ }^{28}$ If women desire treatment, a short course of combined OC (COC) pills for 1 to 3 months could be considered. There is no high quality evidence to support this practice, but clinically it has been shown to be effective in reducing intermenstrual bleeding in certain patients. NSAID use has not been studied in LNG-IUD users as it has in $\mathrm{Cu}-\mathrm{IUD}$ users. NSAIDs are still an excellent option for dysmenorrhea complaints in LNG-IUD users.

\section{Contraceptive implants}

The etonogestrel implant is currently the only form of implantable contraception available in the US. It is a single rod impregnated with $68 \mathrm{mg}$ of etonogestrel that is placed in the upper, inner arm of the patient and approved for 3 years of use. The trade name previously was Implanon but after modification it was remarketed as Nexplanon. The implant is the most effective form of LARC with a failure rate of $0.05 \%$ at 1 year. ${ }^{9}$ Side effects that have been possibly attributed to the implant are headache $(16 \%)$, weight gain $(12 \%)$, acne $(12 \%)$, breast tenderness $(10 \%)$, emotional lability $(6 \%)$, and abdominal pain (5\%). ${ }^{29}$ Continuation rates in one large US prospective trial were $82 \%$ at 1 year, $69 \%$ at 2 years, and $56 \%$ at 3 years. ${ }^{15}$ The most common reason cited for discontinuation is the most common side effect of the implant: unscheduled bleeding. ${ }^{15,29}$ One review of eleven international clinical trials noted nearly an overall $15 \%$ discontinuation rate among users in the US and Europe attributable to unfavorable bleeding profile. ${ }^{29}$

\section{Expected bleeding irregularities and counseling}

Unscheduled light bleeding or spotting is common with implant use, with $78 \%$ of users experiencing some form of irregular bleeding over a 3-month period. ${ }^{29,30}$ In the clinical trials for approval, on average during any 90-day period,
$34 \%$ of women experienced infrequent bleeding, $22 \%$ amenorrhea, 18\% prolonged bleeding, and 7\% frequent bleeding. ${ }^{29,30}$ These bleeding irregularities do not normalize over time but can remain random and unpredictable throughout the 3 years of use. ${ }^{31}$ That being said, the bleeding is not heavy and the median number of bleeding-spotting days is slightly lower than women experiencing natural menstrual cycles. ${ }^{31}$ A favorable bleeding pattern within the first 3 months of use may predict a continued favorable pattern during the remainder of use. ${ }^{30}$ Given the significant rates of unscheduled bleeding, anticipatory counseling should take place prior to placement of the etonogestrel implant. Women should be made aware of the possibility of irregular bleeding and be willing to tolerate a potentially erratic bleeding schedule.

\section{Treatment options}

The benign nature of the bleeding should be emphasized and reassurance offered. If a woman finds the unscheduled bleeding unacceptable, several treatment options are available and should be offered prior to discontinuation of this highly effective LARC. The optimal treatment strategy has not been elucidated, therefore, choice is based on clinical scenario and patient preference. Short courses of NSAIDs (5 to 7 days) can be utilized during days of bleeding. ${ }^{1}$ Ibuprofen is a good choice given that it is readily available and generally well tolerated. Two small studies on the LNG-implant and etonogestrel implant, respectively, found significantly decreased bleeding within 7 days of starting oral celecoxib (200 mg daily for 5 days) or oral mefenamic acid (500 mg three times daily for 5 days) compared to placebo. ${ }^{32,33}$ However, it is important to counsel the patient that this effect is temporary. Exogenous estrogen is an additional option given that it stabilizes the endometrium; data supporting this practice are derived from studies on the LNG-containing implant not available in the US. Combined hormonal contraceptives (CHCs) and estrogen-only therapies for 10 to 20 days are both options for those patients who are medically eligible. ${ }^{1}$ Mifepristone has also been investigated as treatment for unscheduled bleeding in etonogestrel patients and has been found to be effective in causing cessation when combined with ethinyl estradiol or doxycycline (but not alone). ${ }^{34,35}$ However, mifepristone is a highly regulated and expensive medication in the US and would likely be impractical to use for this purpose. If mifepristone is used however, a back-up method for contraception should be employed for 14 days given that the effect of mifepristone on the contraceptive action of the etonogestrel implant is unknown. Other less 
common options that have been investigated are tamoxifen, LNG pills, tranexamic acid, and vitamin E but these are experimental. ${ }^{1}$

\section{Injectables}

Depot medroxyprogesterone acetate (DMPA) is available as an injectable form of contraception in the US (150 mg intramuscular or $104 \mathrm{mg}$ subcutaneous). It is a potent progestin administered every 11 to 14 weeks, depending on formulation. ${ }^{1}$ The failure rate of DMPA is $6 \%$ in the first year with typical use and continuation rates are $57 \%$ at 1 year, $40 \%$ at 2 years, and $33 \%$ at 3 years. ${ }^{9,15}$ Side effects of DMPA may include weight gain (mean $<2 \mathrm{~kg}$ over 12 months), headache, breast tenderness, and mood changes, although a definitive link between some of these and DMPA has not been found. ${ }^{36-38}$ In addition, there have been concerns raised regarding temporary decreased bone mineral density in association with DMPA use, resulting in a US Food and Drug Administration black box warning. However, the best available data suggest that DMPA does not reduce peak bone mass and does not increase risk of fracture with current use or later in life for long-term users. ${ }^{39}$ Bleeding irregularities occur in nearly all women using $\mathrm{DMPA}^{1}$ and is the most common reason for discontinuation ( $25 \%$ of users in the first year). ${ }^{40}$

\section{Expected bleeding irregularities and counseling}

Amenorrhea is common with DMPA, with $10 \%$ to $30 \%$ of users becoming amenorrheic within the first 3 months, 50\% by the first year, and $80 \%$ by 5 years. ${ }^{41,42}$ Similar effects are seen with the subcutaneous version. ${ }^{43}$ In fact, absence of bleeding is the most common bleeding irregularity experienced in continued DMPA users and often the desired effect. Unscheduled spotting or light bleeding is also common with DMPA use and during the first 3 months episodes can last 7 days or longer. The frequency and duration of the episodes decreases over time. ${ }^{1,41}$ Heavy or prolonged bleeding is less common than amenorrhea or light bleeding, but should still be considered an expected side effect. ${ }^{1}$ Women should be counselled that amenorrhea is common with DMPA use. Two studies have been conducted on side effect counseling specifically for DMPA. In a Chinese study, 421 women were randomized to "structured counseling" or "routine counseling" prior to administration of DMPA. ${ }^{44}$ The structured counseling included detailed information regarding the mechanism of action of DMPA and the possible side effects. Women were told that they may experience unscheduled bleeding and that it may improve over time. Also, participants watched an educational video and received an information booklet on DMPA. The routine counseling patients only received information about side effects if they asked. At the end of the study, termination rates were significantly lower in the structured counseling group than the routine counseling group ( $11 \%$ vs $42 \%$ discontinuation at 12 months, $P<0.0001)$. Canto de Cetina et al also investigated the effect of pretreatment counseling on discontinuation rates. ${ }^{45}$ In this study, 350 Mexican women were randomized to either structured pretreatment counseling or routine counseling. The structured counseling included information about common side effects such as the possibility of irregular menstrual periods, heavy bleeding, spotting, and amenorrhea, and emphasized the fact that these side effects were not detrimental to the patient's health. These points were re-discussed at each follow-up visit. The routine counseling group was given standard information on expected side effects. This study also showed significantly decreased discontinuation rates in the structured counseling group (17\% vs $43.4 \%$, $P<0.05)$. Therefore, informing patients that bleeding irregularities are common with DMPA and that only $11 \%$ of users will experience a normal menstrual pattern will very likely decrease discontinuation rates and potentially increase satisfaction. $^{41,44,45}$

\section{Treatment options}

First line intervention for bleeding irregularities in DMPA is reassurance and counseling, as mentioned above. Given that the irregularities tend to decrease over time, many women, with reassurance, find it acceptable to wait for resolution of the symptoms. For those women who find the bleeding profile of DMPA unacceptable, there are several treatment options available. Amenorrhea does not require treatment, but if there are pregnancy symptoms, pregnancy should be ruled out. In women with unscheduled spotting, light or heavy bleeding, a short course of NSAIDs ( 5 to 7 days) may be used during the days of bleeding. ${ }^{1}$ Mefenamic acid (500 mg twice a day for 5 days) has been specifically investigated in a small study and reported to temporarily control unscheduled bleeding during DMPA use. ${ }^{46}$ Valdecoxib (40 mg daily for 5 days) was shown to decrease duration of unscheduled bleeding episodes in a small study, but it is not available in the US. ${ }^{47}$ Add-back estrogen in the form of CHCs for a short period (10 to 20 days) has also been shown to be helpful. ${ }^{1,48-50}$ Additional forms of estrogen such as oral (1.25 mg conjugated estrogen or $2 \mathrm{mg}$ micronized estradiol for 14 days) and transdermal ( $0.1 \mathrm{mg} / 24$-hour estradiol patch) can be utilized as well if there are no contraindications to estrogen. ${ }^{1,28}$ Tranexamic acid (250 mg four times a day for 5 days) 
was effective in controlling unscheduled bleeding in a randomized placebo-controlled trial of 100 DMPA users. ${ }^{51}$ Similarly, a trial demonstrated the effectiveness of mifepristone ( $50 \mathrm{mg}$ once every 2 weeks) in controlling unscheduled bleeding in DMPA users. ${ }^{52}$ However, as mentioned with the etonogestrel implant, mifepristone is a highly regulated medication and difficult to obtain, particularly since the low dose $50 \mathrm{mg}$ formulation is not available in the US. As previously mentioned, if mifepristone is used for this purpose, a back-up method of contraception should be employed for 14 days. Anecdotally, some clinicians opt to shorten the intervals between DMPA injections to reduce unscheduled bleeding especially in obese women, however there is no evidence to support this practice. Doxycycline administration has not been shown to be effective in treating unscheduled bleeding in DMPA users ${ }^{53}$ and asprin has not been studied in this population. ${ }^{1}$

\section{Progestin-only pills}

POPs available in the US contain a small dose $(0.35 \mathrm{mg})$ of norethindrone. POPs are especially useful for women who are not medically eligible to receive estrogen, such as patients with a history of migraine with aura, are over the age of 35 years and smoke $>15$ cigarettes per day, or those who have specific medical comorbidities which could be worsened with estrogen administration. ${ }^{1}$ POPs do not reliably suppress ovulation and work by thickening cervical mucus. The typical use failure rate is $9 \%$ within the first year and the continuation rate at 1 year is $67 \% .^{1,9}$ An important note regarding POPs is the necessity of taking the pill at the same time daily to maintain therapeutic drug levels. As little as a 3-hour late dose requires an additional form of contraception for 48 hours. ${ }^{1}$ The most common side effect, as well as the most commonly cited reason for discontinuation, is unscheduled bleeding.

\section{Expected bleeding irregularities and counseling}

Similar to DMPA, any type of bleeding irregularity can be expected with POPs, including amenorrhea, irregular spotting or prolonged bleeding. ${ }^{36,37} \mathrm{Up}$ to half of POP users will have a monthly menses, ${ }^{54,55}$ but POP users will have more unpredictable bleeding irregularities in both duration and frequency in comparison to COC users. ${ }^{54}$ Approximately $40 \%$ of users will have irregular bleeding and 10\% will have amenorrhea. In addition to counseling women regarding the need to take the pill at the exact same time daily for effectiveness, women should be counselled that bleeding irregularities while using POPs are very common and can occur in any form.

\section{Treatment options}

Given that most women who use POPs do so because of a contraindication to estrogen, the treatment options for unscheduled bleeding are limited. Counseling is the first line intervention, explaining that the bleeding irregularities are likely to be benign. Amenorrhea does not require treatment. However, if a woman believes she may be pregnant based on signs or symptoms, pregnancy testing is appropriate. Taking the POPs at the exact same time daily will minimize the unscheduled bleeding as much as possible. Low dose mifepristone ( $50 \mathrm{mg}$ one dose every 2 weeks) has been shown to be effective in reducing irregular bleeding, but as previously discussed is generally not an option in the US and a back-up method for contraception should be used. ${ }^{56}$

\section{Combined hormonal contraceptives}

$\mathrm{CHCs}$, containing both estrogen and progestin are available in several forms in the US, including pills (COCs), transdermal patch, and a vaginal ring. Traditionally $\mathrm{CHCs}$ are used for 21 to 24 consecutive days followed by a 4 - to 7-day hormone free period. However, $\mathrm{CHCs}$ can also be used continuously for an extended time period. ${ }^{1}$ There are several contraindications and cautions to estrogen-containing medications which are outlined in the US Medical Eligibility Criteria for Contraceptive Use. ${ }^{57}$ The failure rate of CHCs is approximately $9 \%$ in the first year of typical use and the continuation rate is $60 \%$ at 1 year, $42 \%$ at 2 years, and $32 \%$ at 3 years. ${ }^{9,15}$ Side effects of CHCs include bloating, nausea, and breast tenderness, and usually subside within the first 3 months of use. ${ }^{36,37}$ Bleeding irregularities are the most common side effect of CHCs and the bleeding profile varies with the type of $\mathrm{CHC}$ and the formulation.

\section{Expected bleeding irregularities and counseling}

\section{Combined oral contraceptives}

There are a myriad of forms of this type of contraceptive, colloquially known as "the pill". The most common formulations contain 10 to $35 \mu \mathrm{g}$ of ethinyl estradiol. In addition, the estrogen and/or progestin dose can be either constant throughout the cycle (monophasic) or varied (biphasic or triphasic). ${ }^{36,37}$ There is also a new addition to the class, a four-phase pill made with estradiol-dienogest (trade name Natazia), which is approved for treatment of heavy menstrual bleeding given the high amenorrhea rates associated with its use. ${ }^{58}$ Overall, COCs are progestindominant in their effects and decrease menstrual blood loss. Prolonged use of the COC can lead to amenorrhea. 
Unscheduled bleeding is common during the first 3 to 6 months (30\% to $50 \%$ of women initiating) of COC use and decreases over time $(10 \%$ to $30 \%$ of women by the third month of use). ${ }^{1,59}$ After 3 months of use, unscheduled bleeding is most commonly caused by missed pills but can be associated with smoking, medications that interfere with hormone metabolism, and issues with pill absorption due to vomiting and diarrhea. The estrogen dose is also associated with the rate of unscheduled bleeding, with the lowest doses associated with the most episodes. ${ }^{60,61}$ In general, the lower dose estrogen pills ( $20 \mu \mathrm{g}$ or less) are associated with higher discontinuation rates with unscheduled bleeding as the cited reason. ${ }^{61}$ Intermenstrual spotting is slightly more frequent in women initiating continuous regimens (although the majority, $90 \%$, of these women will develop amenorrhea within the first 12 months). One randomized controlled trial demonstrated that after 9 months, those women on continuous COCs experienced overall less unscheduled bleeding days than those on cyclic regimens. ${ }^{62}$ Women on continuous regimens should be counselled that they may experience intermenstrual spotting and lighter menses, but that the unscheduled bleeding does not indicate a decreased efficacy of the contraceptive. ${ }^{1,37}$

\section{Vaginal contraceptive ring}

There is one vaginal contraceptive ring available in the US and it is marketed as Nuvaring. It releases $15 \mu \mathrm{g}$ of ethinyl estradiol and $120 \mu \mathrm{g}$ of etonogestrel daily. The ring is placed in the vagina for 21 days and then removed for 7 days to allow for a withdrawal bleed. ${ }^{36,37}$ Given its steady-state absorption through the vagina, the ring provides cycle control that is similar to or better than that of $\mathrm{COCs}^{48,49}$ and similarly, can be used continuously. ${ }^{37}$ Unscheduled bleeding is a common side effect of the ring, particularly in the first few months of use. ${ }^{37}$ A study of women using the continuous regimen demonstrated more bleeding/spotting days within the first 3 months than cyclic users, but overall less unscheduled bleeding days; the clinical conclusion being that women willing to tolerate occasional spotting but who desire fewer menstrual periods may benefit from a continuous regimen. ${ }^{50}$

\section{Transdermal patch}

There is one transdermal patch available in the US and it is marketed as Xulane, the generic version of Ortho Evra. It delivers $20 \mu \mathrm{g}$ of ethinyl estradiol and $150 \mu \mathrm{g}$ of norelgestromin daily. A new patch is applied weekly for 3 weeks, and then one patch-free week to allow for withdrawal bleeding. ${ }^{36,37}$ Unscheduled bleeding is the most common side effect in the first two cycles of use and is comparable in frequency and pattern to COCs. The unscheduled bleeding decreases substantially in the first 6 to 12 months of use. ${ }^{63}$ Women using the patch should be counselled that bleeding irregularities including spotting or unscheduled light bleeding are common in the first 3 months of use but decrease substantially by 6 months. Continuous use of the transdermal patch has only been evaluated in one study. ${ }^{64}$ Given the higher exposure to estrogen with the patch compared to OCs, ${ }^{65}$ some clinicians prefer not to prescribe the patch in a continuous fashion.

\section{Treatment options}

First line intervention for unscheduled bleeding is reassurance and counseling that the bleeding irregularities are generally not harmful and improve over time. ${ }^{1}$ Reinforcement of consistent use is paramount, given that most unscheduled bleeding with COCs (60\% to $70 \%)$ is secondary to a missed pill. ${ }^{66}$ Additionally, given that such a large proportion of breakthrough bleeding is related to missed doses, switching a patient from COCs to either the patch or ring (which do not require daily compliance) may be effective in reducing total number of episodes. ${ }^{37}$ If women are bothered by these symptoms and desire treatment beyond what is mentioned above there are several options. These vary by whether women are using a cyclic regimen or continuous regimen.

- Cyclic regimen: if the irregular bleeding persists beyond the first 3 months of use and the woman desires treatment, changing formulations is one option. Unscheduled bleeding that occurs during the active pills may indicate a need for increased endometrial support by increasing progestin content. Unscheduled bleeding after the withdrawal bleed, in contrast, may indicate a need for more estrogen. This can be accomplished by increasing the estrogen dose of the pill ${ }^{61}$ or decreasing the progestin content of the first pills (triphasic). ${ }^{59}$ With the complaint of amenorrhea, if a woman desires a monthly withdrawal bleed, switching to a pill formulation with a higher dose of estrogen or a triphasic formulation with lower progestin amounts at the beginning of the cycle may help. Finally, for persistent unscheduled bleeding, a short course of estrogen $(1.25 \mathrm{mg}$ conjugated estrogen or $2 \mathrm{mg}$ estradiol for 7 days) during the hormone free interval has been recommended by experts. $^{37}$

- Continuous regimen: for unscheduled bleeding with continuous $\mathrm{CHC}$ use, changing dosing and formulation can be useful. In one study, those women using a $30 \mu \mathrm{g}$ pill experienced significantly less unscheduled bleeding than those using a $20 \mu \mathrm{g}$ pill. ${ }^{67} \mathrm{In}$ a different study, pills 


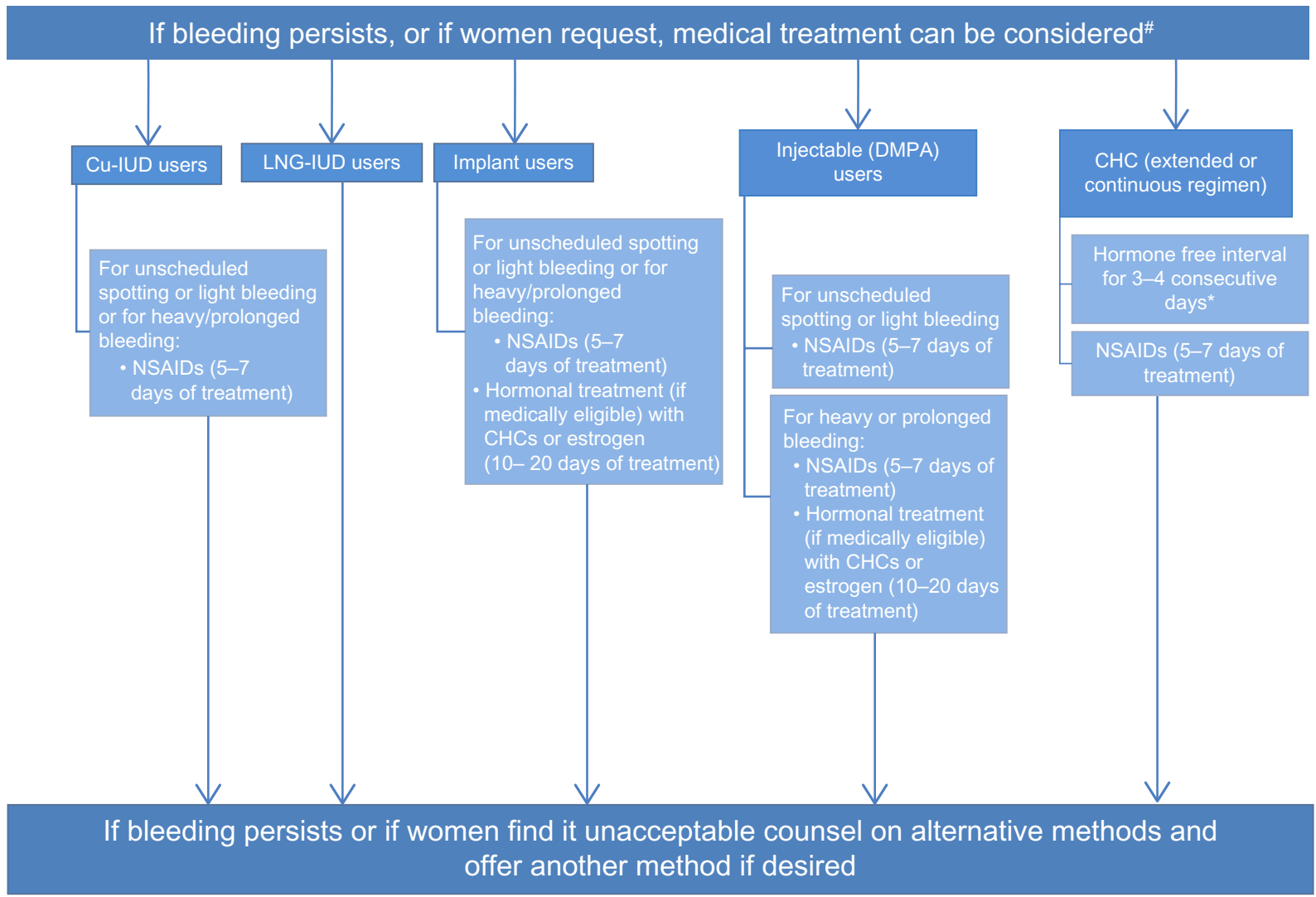

Figure I Management of women with bleeding irregularities while using contraception.

Notes: "If clinically warranted, evaluate for underlying condition. Treat the condition or refer for care. *Not recommended during first 21 days of extended or continuous pill or ring use; not recommended more than once per month because contraceptive effectiveness may be reduced. Adapted from: cdc.gov [homepage on the Internet]. U.S. Selected Practice Recommendations for Contraceptive Use, 2013: Centers for Disease Control and Prevention; 20I3. Available from: http://www.cdc.gov/mmwr/preview/ mmwrhtml/rr6205al.htm. Accessed February 5, 2016.'

Abbreviations: Cu-IUD, copper intrauterine device; LNG, levonorgestrel; DMPA, depot medroxyprogesterone acetate; CHC, combined hormonal contraceptive; NSAIDs, non-steroidal anti-inflammatory drugs.

formulated with LNG had significantly less unscheduled bleeding than those formulated with norethindrone. ${ }^{68}$ Additionally, discontinuation of the continuous $\mathrm{CHC}$ for 3 to 4 days in cases of bothersome unscheduled bleeding to allow for a withdrawal bleed is one option, as long as the discontinuation occurs after the first 21 days of use. ${ }^{1}$ However, this technique is limited to once every 3 weeks, given the risk of decreasing contraceptive effectiveness. Doxycycline is not effective for unscheduled bleeding in women using continuous regimens. ${ }^{69}$

\section{Conclusion}

Increasing satisfaction with contraception is important to help women feel comfortable with the method and continue its use. The most common reason for stopping a contraceptive method completely (not interruption of a method) due to dissatisfaction is the bleeding profile. An algorithm to manage bleeding irregularities in women using contraception is shown in Figure 1. As mentioned, discontinuation rates vary based on the method of birth control, with LARCs having the highest satisfaction and lowest discontinuation rate (and the highest effectiveness)., ${ }^{49}$ This review has outlined both the expected and unexpected bleeding irregularities with each method, as well as various treatment options for those bleeding irregularities. In some settings, structured counseling and reassurance regarding the bleeding profile and likely benign nature of the irregular bleeding has been shown to decrease discontinuation rates.

\section{Disclosure}

Dr Jennifer Villavicencio has no conflicts of interest to disclose. Dr Rebecca H Allen is a Nexplanon trainer for Merck, a Liletta trainer for Actavis, and has consulted for Bayer on IUDs.

\section{References}

1. cdc.gov [homepage on the Internet]. U.S. Selected Practice Recommendations for Contraceptive Use, 2013: Adapted from the World Health Organization Selected Practice Recommendations for Contraceptive Use, 2nd Edition. Centers for Disease Control and Prevention; 2013. Available from: http://www.cdc.gov/mmwr/preview/mmwrhtml/rr6205a1.htm. Accessed February 5, 2016. 
2. Inoue $\mathrm{K}$, Barratt A, Richters J. Does research into contraceptive method discontinuation address women's own reasons? A critical review. J Fam Plann Reprod Health Care. 2015;41(4):292-299.

3. Westhoff CL, Heartwell S, Edwards S, et al. Oral contraceptive discontinuation: do side effects matter? Am J Obstet Gynecol. 2007; 196(4):412.e1-e6.

4. Moreau C, Cleland K, Trussell J. Contraceptive discontinuation attributed to method dissatisfaction in the United States. Contraception. 2007;76(4):267-272.

5. Grunloh DS, Casner T, Secura GM, Peipert JF, Madden T. Characteristics associated with discontinuation of long-acting reversible contraception within the first 6 months of use. Obstet Gynecol. 2013;122(6):1214-1221.

6. Mishell DR Jr, Guillebaud J, Westhoff C, et al. Recommendations for standardization of data collection and analysis of bleeding in combined hormone contraceptive trials. Contraception. 2007;75(1): $11-15$.

7. Halpern V, Lopez LM, Grimes DA, Stockton LL, Gallo MF. Strategies to improve adherence and acceptability of hormonal methods of contraception. Cochrane Database Syst Rev. 2013;10:CD004317.

8. Modesto W, Bahamondes MV, Bahamondes L. A randomized clinical trial of the effect of intensive versus non-intensive counseling on discontinuation rates due to bleeding disturbances of three long-acting reversible contraceptives. Hum Reprod. 2014;29(7) 1393-1399.

9. Trussell J. Contraceptive failure in the United States. Contraception. 2011;83(5):397-404.

10. Diedrich JT, Desai S, Zhao Q, Secura G, Madden T, Peipert JF. Association of short-term bleeding and cramping patterns with longacting reversible contraceptive method satisfaction. Am J Obstet Gynecol. 2015;212(1):50.e51-e58.

11. Hubacher D, Chen PL, Park S. Side effects from the copper IUD: do they decrease over time? Contraception. 2009;79(5):356-362.

12. Andrade AT, Pizarro Orchard E. Quantitative studies on menstrual blood loss in IUD users. Contraception. 1987;36(1):129-144.

13. Hassan EO, el-Husseini M, el-Nahal N. The effect of 1-year use of the CuT 380A and oral contraceptive pills on hemoglobin and ferritin levels. Contraception. 1999;60(2):101-105.

14. Milsom I, Andersson K, Jonasson K, Lindstedt G, Rybo G. The influence of the Gyne-T 380S IUD on menstrual blood loss and iron status. Contraception. 1995;52(3):175-179.

15. Diedrich JT, Zhao Q, Madden T, Secura GM, Peipert JF. Three-year continuation of reversible contraception. Am J Obstet Gynecol. 2015;213(5):662.e1-e8.

16. Grimes DA, Hubacher D, Lopez LM, Schulz KF. Non-steroidal anti-inflammatory drugs for heavy bleeding or pain associated with intrauterine-device use. Cochrane Database Syst Rev. 2006;(4):CD006034.

17. Godfrey EM, Folger SG, Jeng G, Jamieson DJ, Curtis KM. Treatment of bleeding irregularities in women with copper-containing IUDs: a systematic review. Contraception. 2013;87(5):549-566.

18. Ylikorkala O, Viinikka L. Comparison between antifibrinolytic and antiprostaglandin treatment in the reduction of increased menstrual blood loss in women with intrauterine contraceptive devices. Br JObstet Gynaecol. 1983;90(1):78-83.

19. Pedron N, Lozano M, Gallegos AJ. The effect of acetylsalicylic acid on menstrual blood loss in women with IUDs. Contraception. 1987;36(3):295-303.

20. Mercorio F, De Simone R, Di Carlo C, et al. Effectiveness and mechanism of action of desmopressin in the treatment of copper intrauterine device-related menorrhagia: a pilot study. Hum Reprod. 2003;18(11):2319-2322.

21. Kaunitz AM, Bissonnette F, Monteiro I, Lukkari-Lax E, Muysers C, Jensen JT. Levonorgestrel-releasing intrauterine system or medroxyprogesterone for heavy menstrual bleeding: a randomized controlled trial. Obstet Gynecol. 2010;116(3):625-632.

22. Mirena (levonorgestrel-releasing intrauterine system) [package insert]. Whippany, NJ: Bayer HealthCare Pharmaceuticals Inc; 2015.
23. Hidalgo M, Bahamondes L, Perrotti M, Diaz J, Dantas-Monteiro C, Petta C. Bleeding patterns and clinical performance of the levonorgestrelreleasing intrauterine system (Mirena) up to two years. Contraception. 2002;65(2):129-132.

24. Eisenberg DL, Schreiber CA, Turok DK, et al. Three-year efficacy and safety of a new 52-mg levonorgestrel-releasing intrauterine system. Contraception. 2015;92(1):10-16.

25. Liletta (levonorgestrel-releasing intrauterine system) [package insert]. Parsippany, NJ: Actavis Pharma, Inc.; 2015.

26. Gemzell-Danielsson K, Schellschmidt I, Apter D. A randomized, phase ii study describing the efficacy, bleeding profile, and safety of two low-dose levonorgestrel-releasing intrauterine contraceptive systems and Mirena. Fertil Steril. 2012;97(3):616-622.e1-e3.

27. Skyla (levonorgestrel-releasing intrauterine system) [package insert]. Wayne, NJ: Bayer HealthCare Pharmaceuticals Inc.; 2015.

28. Abdel-Aleem H, d'Arcangues C, Vogelsong KM, Gaffield ML, Gulmezoglu AM. Treatment of vaginal bleeding irregularities induced by progestin only contraceptives. Cochrane Database Syst Rev. 2013;10:CD003449.

29. Darney P, Patel A, Rosen K, Shapiro LS, Kaunitz AM. Safety and efficacy of a single-rod etonogestrel implant (Implanon): results from 11 international clinical trials. Fertil Steril. 2009;91(5):1646-1653.

30. Mansour D, Korver T, Marintcheva-Petrova M, Fraser IS. The effects of Implanon on menstrual bleeding patterns. Eur J Contracept Reprod Health Care. 2008;13 Suppl 1:13-28.

31. Mansour D, Bahamondes L, Critchley H, Darney P, Fraser IS. The management of unacceptable bleeding patterns in etonogestrelreleasing contraceptive implant users. Contraception. 2011;83(3): 202-210.

32. Buasang K, Taneepanichskul S. Efficacy of celecoxib on controlling irregular uterine bleeding secondary to Jadelle use. J Med Assoc Thai. 2009;92(3):301-307.

33. Phaliwong $\mathrm{P}$, Taneepanichskul S. The effect of mefenamic acid on controlling irregular uterine bleeding second to Implanon use. J Med Assoc Thai. 2004;87 Suppl 3:S64-S68.

34. Weisberg E, Croxatto HB, Findlay JK, Burger HG, Fraser IS A randomized study of the effect of mifepristone alone or in conjunction with ethinyl estradiol on ovarian function in women using the etonogestrel-releasing subdermal implant, Implanon ${ }^{\circledR}$. Contraception. 2011;84(6):600-608.

35. Cheng L, Zhu H, Wang A, Ren F, Chen J, Glasier A. Once a month administration of mifepristone improves bleeding patterns in women using subdermal contraceptive implants releasing levonorgestrel. Hum Reprod. 2000;15(9):1969-1972.

36. Hoffman BL, Schorge JO, Bradshaw KD, Halvorson LM, Schaffer JI, Corton MM, editors. Williams Gynecology. 3rd ed. New York: McGrawHill Education; 2016.

37. Speroff L, Darney PD. A Clinical Guide for Contraception. 5th ed. Philadelphia: Wolters Kluwer Health/Lippincott Williams and Wilkins; 2011.

38. Lopez LM, Edelman A, Chen M, Otterness C, Trussell J, Helmerhorst FM. Progestin-only contraceptives: effects on weight. Cochrane Database Syst Rev. 2013;7:CD008815

39. Kaunitz AM, Arias R, McClung M. Bone density recovery after depot medroxyprogesterone acetate injectable contraception use. Contraception. 2008;77(2):67-76.

40. Cromer BA, Smith RD, Blair JM, Dwyer J, Brown RT. A prospective study of adolescents who choose among levonorgestrel implant (Norplant), medroxyprogesterone acetate (Depo-Provera), or the combined oral contraceptive pill as contraception. Pediatrics. 1994;94(5): 687-694.

41. Hubacher D, Lopez L, Steiner MJ, Dorflinger L. Menstrual pattern changes from levonorgestrel subdermal implants and DMPA: systematic review and evidence-based comparisons. Contraception 2009;80(2):113-118.

42. Belsey EM. Vaginal bleeding patterns among women using one natural and eight hormonal methods of contraception. Contraception. 1988;38(2):181-206. 
43. Arias RD, Jain JK, Brucker C, Ross D, Ray A. Changes in bleeding patterns with depot medroxyprogesterone acetate subcutaneous injection $104 \mathrm{mg}$. Contraception. 2006;74(3):234-238.

44. Lei ZW, Wu SC, Garceau RJ, et al. Effect of pretreatment counseling on discontinuation rates in Chinese women given depo-medroxyprogesterone acetate for contraception. Contraception. 1996;53(6):357-361.

45. Canto De Cetina TE, Canto P, Ordonez Luna M. Effect of counseling to improve compliance in Mexican women receiving depotmedroxyprogesterone acetate. Contraception. 2001;63(3):143-146.

46. Tantiwattanakul P, Taneepanichskul S. Effect of mefenamic acid on controlling irregular uterine bleeding in DMPA users. Contraception. 2004;70(4):277-279.

47. Nathirojanakun P, Taneepanichskul S, Sappakitkumjorn N. Efficacy of a selective Cox-2 inhibitor for controlling irregular uterine bleeding in DMPA users. Contraception. 2006;73(6):584-587.

48. Westhoff C, Osborne LM, Schafer JE, Morroni C. Bleeding patterns after immediate initiation of an oral compared with a vaginal hormonal contraceptive. Obstet Gynecol. 2005;106(1):89-96.

49. Bjarnadottir RI, Tuppurainen M, Killick SR. Comparison of cycle control with a combined contraceptive vaginal ring and oral levonorgestrel/ ethinyl estradiol. Am J Obstet Gynecol. 2002;186(3):389-395.

50. Miller L, Verhoeven CH, Hout J. Extended regimens of the contraceptive vaginal ring: a randomized trial. Obstet Gynecol. 2005;106(3): 473-482.

51. Senthong AJ, Taneepanichskul S. The effect of tranexamic acid for treatment irregular uterine bleeding secondary to DMPA use. J Med Assoc Thai. 2009;92(4):461-465.

52. Jain JK, Nicosia AF, Nucatola DL, Lu JJ, Kuo J, Felix JC. Mifepristone for the prevention of breakthrough bleeding in new starters of depomedroxyprogesterone acetate. Steroids. 2003;68(10-13):1115-1119.

53. Abdel-Aleem H, Shaaban OM, Abdel-Aleem MA, Fetih GN. Doxycycline in the treatment of bleeding with DMPA: a double-blinded randomized controlled trial. Contraception. 2012;86(3):224-230.

54. McCann MF, Potter LS. Progestin-only oral contraception: a comprehensive review. Contraception. 1994;50(6 Suppl 1):S1-S195.

55. Broome M, Fotherby K. Clinical experience with the progestogen-only pill. Contraception. 1990;42(5):489-495.

56. Gemzell-Danielsson K, van Heusden AM, Killick SR, et al. Improving cycle control in progestogen-only contraceptive pill users by intermittent treatment with a new anti-progestogen. Hum Reprod. 2002; 17(10):2588-2593.

57. cdc.gov [homepage on the Internet]. Unites States Medical Eligibility Criteria (US MEC) for Contraceptive Use, 2010. Centers for Disease Control and Prevention; 2010 [updated September 24, 2015]. Available from: http://www.cdc.gov/reproductivehealth/unintendedpregnancy/ usmec.htm. Accessed February 6, 2016.
58. Jensen JT, Parke S, Mellinger U, Machlitt A, Fraser IS. Effective treatment of heavy menstrual bleeding with estradiol valerate and dienogest: a randomized controlled trial. Obstet Gynecol. 2011;117(4): 777-787.

59. Hatcher RA, Trussell J, Nelson AL, Cates W Jr, Stewart FH, Kowal D, editors. Contraceptive Technology. 19th revised edition. New York, NY: Ardent Media; 2007.

60. Rosenberg MJ, Meyers A, Roy V. Efficacy, cycle control, and side effects of low- and lower-dose oral contraceptives: a randomized trial of 20 micrograms and 35 micrograms estrogen preparations. Contraception. 1999;60(6):321-329.

61. Gallo MF, Nanda K, Grimes DA, Schulz KF. 20 mcg versus $>20 \mathrm{mcg}$ estrogen combined oral contraceptives for contraception. Cochrane Database Syst Rev. 2005;(2):CD003989.

62. Miller L, Hughes JP. Continuous combination oral contraceptive pills to eliminate withdrawal bleeding: a randomized trial. Obstet Gynecol. 2003;101(4):653-661.

63. Burkman RT. Transdermal hormonal contraception: benefits and risks. Am J Obstet Gynecol. 2007;197(2):134.e1-e1.

64. Stewart FH, Kaunitz AM, Laguardia KD, Karvois DL, Fisher AC, Friedman AJ. Extended use of transdermal norelgestromin/ethinyl estradiol: a randomized trial. Obstet Gynecol. 2005;105(6):1389-1396.

65. Ortho Evra (norelgestromin/ethinyl estradiol transdermal system) [product information]. Raritan, NJ: Ortho-McNeil-Janssen Pharmaceuticals, Inc.; 2010.

66. Rosenberg MJ, Waugh MS, Higgins JE. The effect of desogestrel, gestodene, and other factors on spotting and bleeding. Contraception. 1996;53(2):85-90.

67. Endrikat J, Muller U, Dusterberg B. A twelve-month comparative clinical investigation of two low-dose oral contraceptives containing 20 micrograms ethinylestradiol/75 micrograms gestodene and 30 micrograms ethinylestradiol/75 micrograms gestodene, with respect to efficacy, cycle control, and tolerance. Contraception. 1997;55(3):131-137.

68. Edelman AB, Koontz SL, Nichols MD, Jensen JT. Continuous oral contraceptives: are bleeding patterns dependent on the hormones given? Obstet Gynecol. 2006;107(3):657-665.

69. Kaneshiro B, Edelman A, Carlson N, Morgan K, Nichols M, Jensen J. Treatment of unscheduled bleeding in continuous oral contraceptive users with doxycycline: a randomized controlled trial. Obstet Gynecol. 2010;115(6):1141-1149.
Open Access Journal of Contraception

\section{Publish your work in this journal}

Open Access Journal of Contraception is an international, peerreviewed, open access, online journal, publishing original research, reports, reviews and commentaries on all areas of contraception. In addition to clinical research, demographics and health-related aspects, the journal welcomes new findings in animal and preclinical studies

\section{Dovepress}

relating to understanding the biological mechanisms and practical development of new contraceptive agents. The manuscript management system is completely online and includes a very quick and fair peer-review system. Visit http://www.dovepress.com/testimonials.php to read real quotes from published authors. 